\title{
COMMUNICABLE DISEASES REPORT, NEW SOUTH WALES, FOR NOVEMBER AND DECEMBER 2005
}

For updated information, including data and facts on specific diseases, visit www.health.nsw.gov.au and click on Infectious Diseases.

\section{TRENDS}

Tables 2 and 3 and Figure 1 show reports of communicable diseases received through to the end of November and December 2005 for each area health service in NSW.

\section{ENTERIC DISEASE}

\section{Cryptosporidiosis}

The number of people reported with cryptosporidiosis increased from 51 cases in October to 143 cases in November. There were 100 cases in December. Cryptosporidiosis occurs after ingestion of the parasite Cryptosporidium and is characterised by watery diarrhoea, abdominal cramps, vomiting and occasionally fever. Symptoms can last for many weeks or even months in some people. No specific treatment is recommended, other than supportive care.

In response to the increase, NSW public health units were asked to interview all patients, using a standard form to identify risk factors for illness. Interviews identified no single source for the outbreak. However, most cases (75 per cent) were from rural parts of the state, and some people reported having direct contact with farm animals, visiting farms, drinking untreated water, or swimming in rivers and pools. The Department of Primary Industries reports that there has been a recent increase in calves with scours (diarrhoea that can be caused by Cryptosporidium infection). While investigations continue, these data suggest that the outbreak may have begun when a small number of people acquired the illness from infected animals, either through direct contact, contact with the animals' faeces, or from contaminated waterways in which they swam or from which they drank untreated water. Once in humans, the infection is readily transmitted through person-to-person contact. A major public health concern is that recovering cases will unwittingly carry the parasite into swimming pools where the chlorine resistance of the organism allows it to remain infectious for weeks. Consequently, swimmers who swallow small amounts of pool water will be at increased risk of acquiring the infection. A massive outbreak of cryptosporidiosis occurred across NSW in 1998 after several pools were contaminated in this way. ${ }^{1}$

To avoid infection people should:

- thoroughly wash their hands with soap and running water for at least 10 seconds after handling animals or their manure; before handling food; after using the toilet; and after changing nappies

- avoid getting water in their mouth when swimming

- avoid drinking untreated water.
Water taken directly from a creek, river or lake should be brought to a rolling boil (and allowed to cool) before drinking. Otherwise the water should be filtered and disinfected using a treatment system certified against the standards to remove Cryptosporidium (for example, AS/NZS 4348 or NASI/NSF 53).

To avoid contaminating swimming facilities, people who have had a diarrhoeal illness should not enter a swimming area for at least one week after complete recovery.

Reference

1. Puech MC, McAnulty JM, Lesjak M, Shaw N, Heron L, Watson JM. A statewide outbreak of cryptosporidiosis in New South Wales associated with swimming at public pools. Epidemiol Infect 2001; 126: 389-96.

\section{Other enteric infections}

Several outbreaks of other enteric diseases were reported in November and December. Notable among these were:

- an increase in cases of infection with Salmonella typhimurium phage type 44 (STm44) across NSW with a total of 14 cases reported in November, including one cluster of five people who had consumed, on different days, a chicken Caesar salad wrap from a retailer in the South Eastern Sydney/Illawarra area. The NSW Food Authority (NSWFA) confirmed that the wrap was prepared using raw egg. Samples of product from the establishment tested negative for Salmonella, but a further trace-back of eggs by the NSWFA is underway. In December a further 32 cases of STm44 were reported. Among these were three clusters:

- seven people who attended a dinner party in the South Eastern Sydney/Illawarra area. Two of the seven were confirmed as having STm44 infection, and one of these two was admitted to hospital. Among the foods eaten was a tiramisu cake prepared using raw egg

- four people from the Central Coast. The source of the cluster remains unclear, and the investigation is continuing

- three people in a residential facility on the North Coast.

- an outbreak of seven cases of Salmonella Singapore infection in the Sydney West area in December. Public health unit staff interviewed the patients and found that the source was likely to have been food served at a wedding and then served as leftovers at a church gathering the next day. In addition to the seven confirmed cases, many other wedding guests reported diarrhoeal illness after the wedding. Among high risk items served at the wedding (and as leftovers) were home prepared potato salad, pork and meatballs. 
- an increase in cases of infection with Salmonella typhimurium phage type 135a across the state

- an outbreak of gastroenteritis among 23 of 29 attendees of a party in November, most likely due to Clostridium perfringens contamination of prepared foods

- nine cases of scombroid fish poisoning linked to eating fish in the Sydney South West and South Eastern Sydney/Illawarra areas in November. Scombroid poisoning occurs after a person ingests fish that contains high levels of histamine that has been produced in the flesh, generally when the fish has been mishandled. Symptoms develop within a few hours of eating the fish, and include tingling and burning around the mouth, facial flushing, sweating, nausea, vomiting, headaches and palpitations. Eight of the cases reported eating tuna before the onset of the illness, and the remaining patient could not specify the type of fish consumed

Notification of both STm135a and STm44 infections have increased in several Australian states in recent weeks. A national investigation, including multi-state case-control studies, is underway in an attempt to identify the likely sources of infection.

Nine cases of infection with verotoxigenic $\boldsymbol{E}$. coli have been notified in the Hunter area in 2005, including six notified since 28 November. No links among the cases have been detected to date. The recent increase in notification may relate to changes in laboratory testing procedures by the reporting laboratory.

\section{AVIAN INFLUENZA}

In December, under the NSW Public Health Act 1991, the diagnosis of avian influenza in humans became notifiable by doctors, hospitals and laboratories. Avian influenza is primarily a disease of birds, and human infection is very rare. Currently it is unlikely that people with avian influenza will present to doctors in Australia, but if they do, it is important that they be identified and isolated as quickly as possible. A doctor may suspect that a patient has avian influenza if the person:

- has a fever and respiratory symptoms, and

- has travelled to a part of the world where avian influenza is prevalent (currently mainly in parts of Asia and eastern Europe) within seven days of onset of symptoms, and

- had contact with poultry, dead birds, or patients (or samples from patients) with avian influenza.
The patient should be advised to wear a surgical mask, be isolated, and be managed as clinically appropriate. The local public health unit should be informed.

On 23 December 2005, the Department of Primary Industries reported that a chicken from a backyard flock in Wentworth (Greater Western Area Health Service) had tested positive, in preliminary testing, for avian influenza. Some of the chickens in the small flock had died in the preceding weeks. A thorough investigation by animal health experts, however, found that the cause of death in the chicken was Marek's disease (a common viral disease of poultry), and in repeat testing, avian influenza was ruled out. As a precaution, public health unit staff identified the people who had had contact with the chickens, and prepared for further actions (such as accessing personal protective equipment and the antiviral neuraminidase inhibitors) had the diagnosis been confirmed.

\section{Pandemic planning}

The NSW Health Interim Influenza Pandemic Action Plan was released in November 2005. The Plan is available on the NSW Health web site (see: www.health.nsw.gov. au/infect/pandemic_flu.html), with links to other resources including advice on infection control. NSW Health will keep this page updated with the latest information on pandemic preparedness, as well as information on the current avian influenza outbreak occurring overseas. NSW Health is working with a range of doctors (including nominees of the NSW General Practice Council) and scientists to better define the roles of different health care workers in the event of a pandemic.

\section{HIV SURVEILLANCE}

Notifications of people newly diagnosed with HIV infection in NSW from 1981 through to June 2005 are shown in Table 1. The annual number of notifications had been generally declining in NSW from the mid-1980s until 2001, when there were 338 notifications. However, case notifications increased in 2002 and again in 2003 to 415 (a 23 per cent increase over the 2 -year period). Notifications declined a little in 2004 (to 404), but in the first half of 2005 alone, 230 have been reported, indicating a further rise. Among the 2005 notifications to date, men who have sex with men were slightly more commonly reported ( 72 per cent) than in previous recent years (less than 70 per cent). The increase in notifications among women seen in 2004 (60 compared with less than 33 in previous recent years) does not appear to have been sustained in 2005; the reason for this short-lived increase is unclear. 붕 


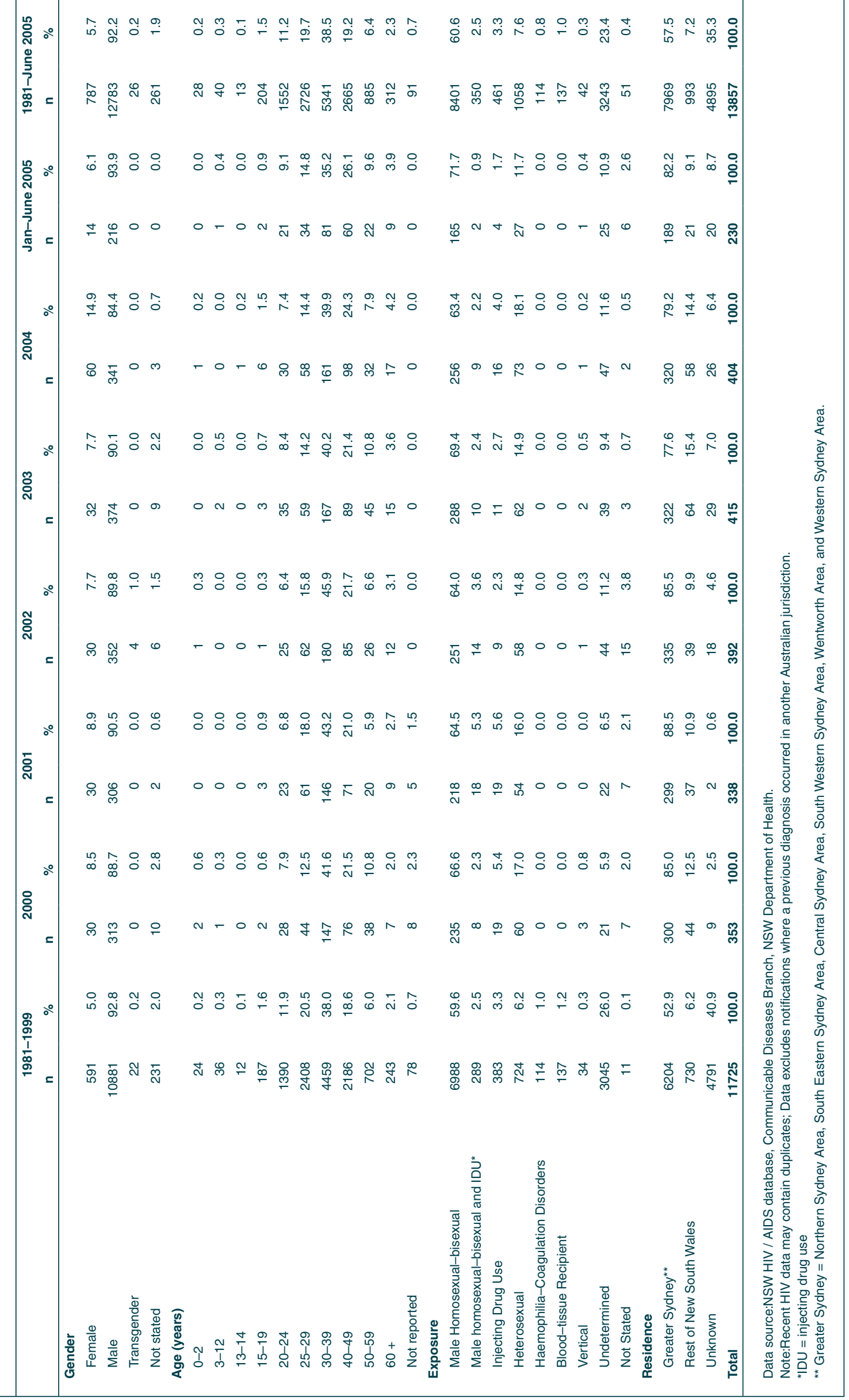


FIGURE 1

\section{REPORTS OF SELECTED COMMUNICABLE DISEASES, NSW, JAN 2000 TO DEC 2005, BY MONTH OF ONSET}

Preliminary data: case counts in recent months may increase because of reporting delays.

Laboratory-confirmed cases only, except for measles, meningococcal disease and pertussis $\mathrm{BFV}=$ Barmah Forest virus infections,

RRV = Ross River virus infections

Lab conf $=$ laboratory confirmed
Men $\mathrm{Gp} \mathrm{C}$ and $\mathrm{Gp} \mathrm{B}=$ meningococcal disease due to serogroup $C$ and serogroup $B$ infection, other/unk = other or unknown serogroups.

NB: multiple series in graphs are stacked, except gastroenteritis outbreaks.

NB: Outbreaks are more likely to be reported by nursing homes and hospitals than by other institutions

\begin{tabular}{lr}
\hline \multicolumn{2}{|l|}{ NSW population } \\
Male & $50 \%$ \\
$<5$ yrs & $7 \%$ \\
$5-24$ yrs & $27 \%$ \\
$25-64$ yrs & $53 \%$ \\
$65+$ yrs & $13 \%$ \\
Rural & $46 \%$
\end{tabular}

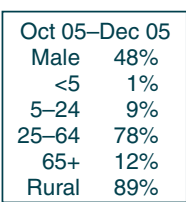

Rural $89 \%$
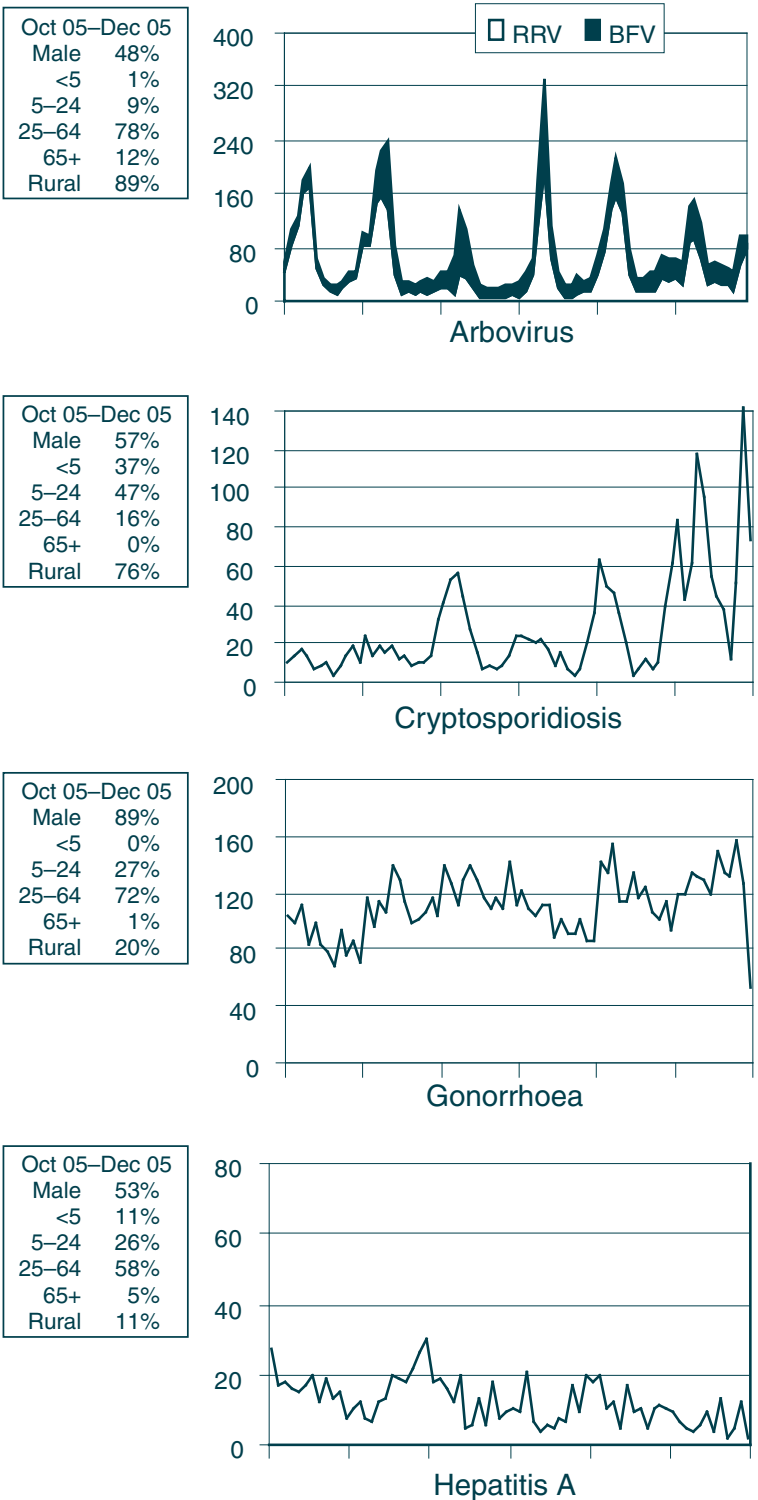

\begin{tabular}{|lr|}
\hline \multicolumn{2}{|c|}{ Oct 05-Dec 05} \\
All outbreaks & 35 \\
Nursing homes & 12 \\
Hospitals & 15 \\
Child care & 7 \\
Schools & 0 \\
Other & 1 \\
\hline
\end{tabular}

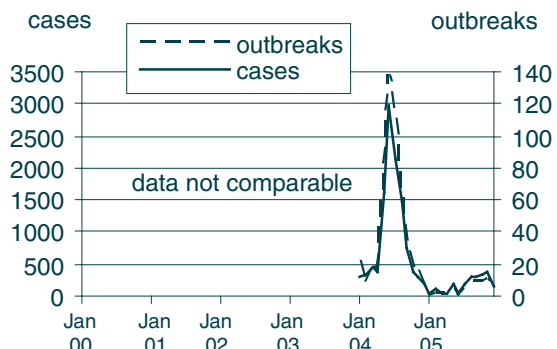

Gastroenteritis outbreaks in institutions
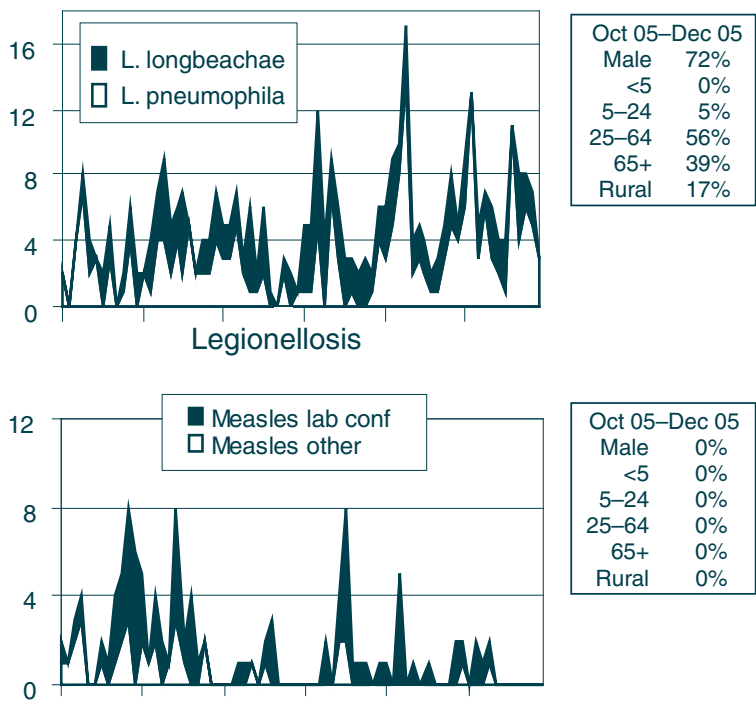

Measles
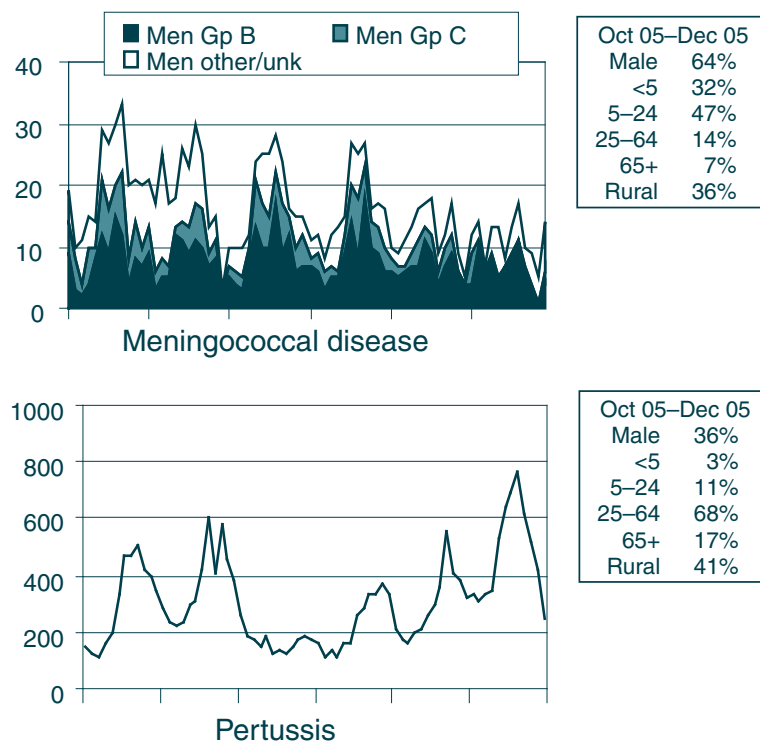

Pertussis
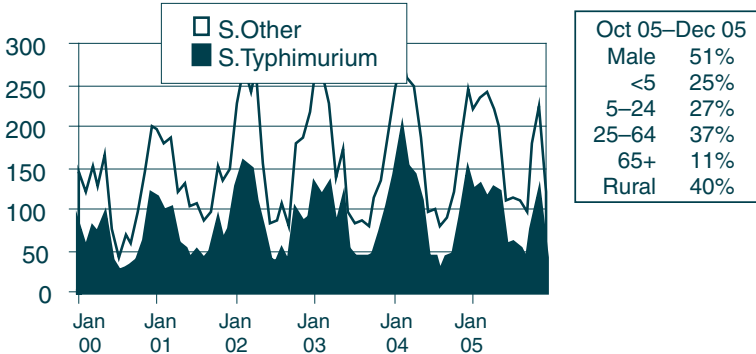

Salmonella infections 


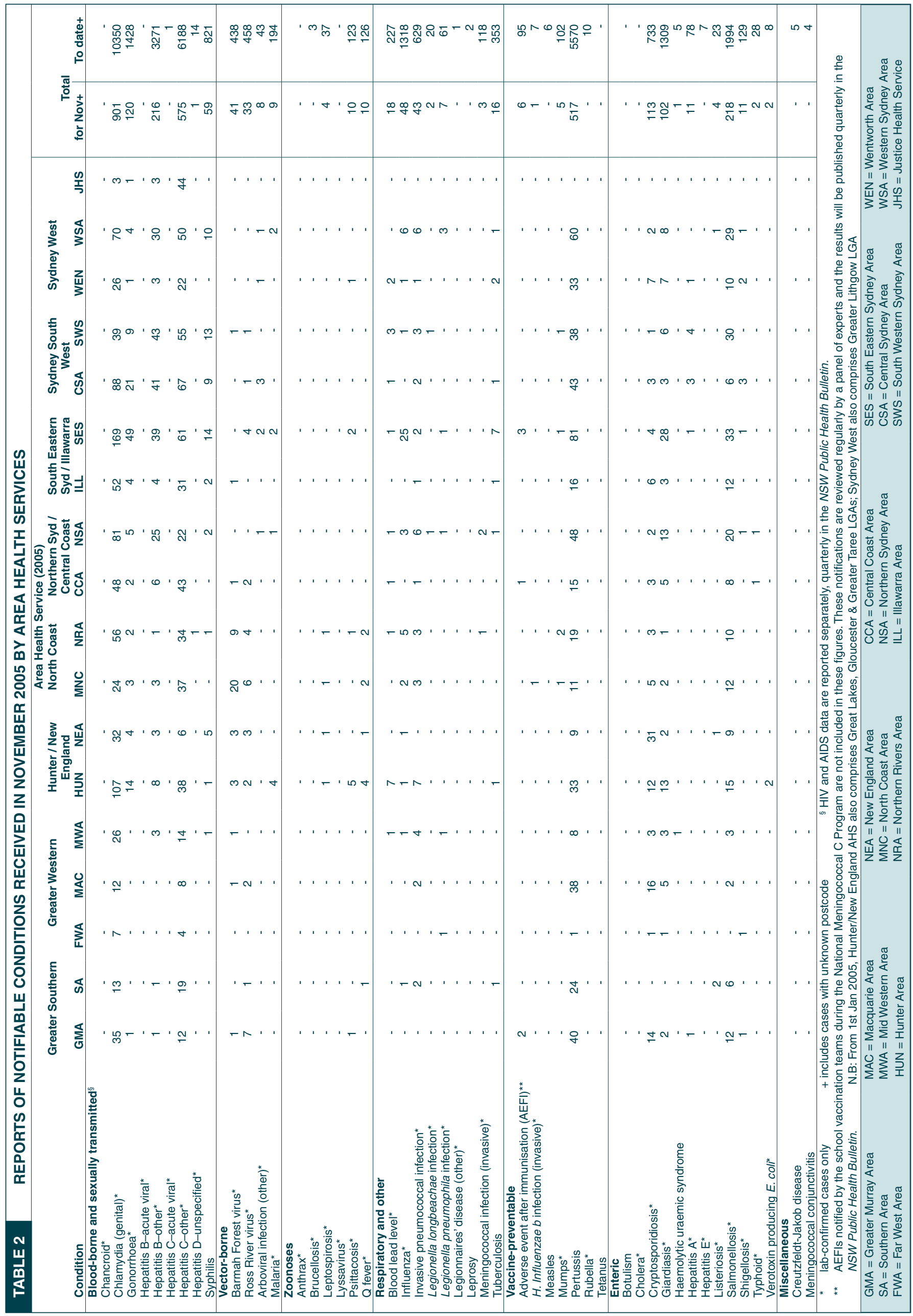




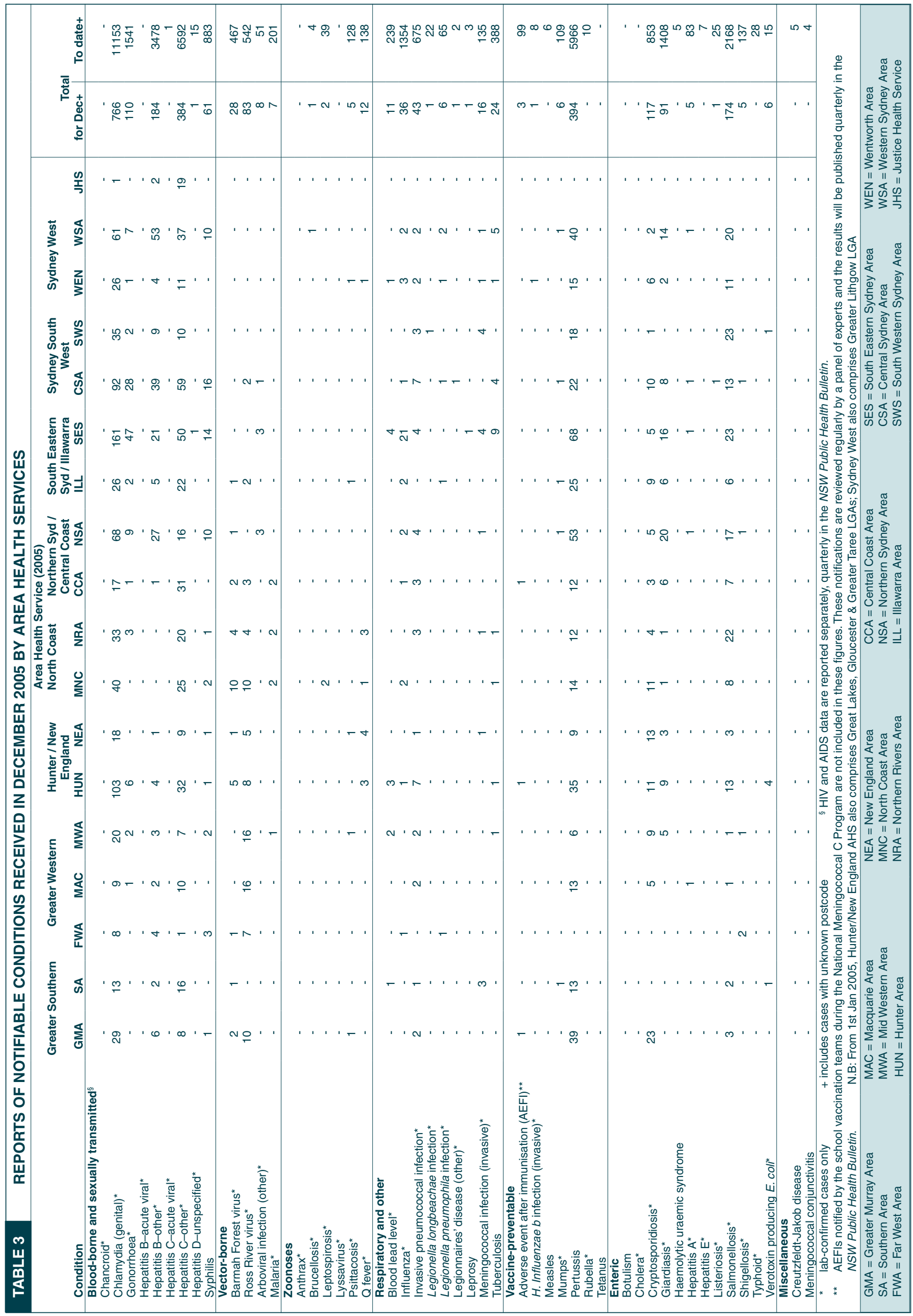

